\title{
RESEARCH
}

Open Access

\section{Dental follicle stem cells rescue the regenerative capacity of inflamed rat dental pulp through a paracrine pathway}

\author{
Hong Hong ${ }^{1 \dagger}$, Xiaochuan Chen ${ }^{1,2+}$, Kun $\mathrm{Li}^{3}$, Nan Wang ${ }^{3}$, Mengjie Li ${ }^{1}$, Bo Yang ${ }^{1}$, Xiaoqi Yu ${ }^{3 *}$ and Xi Wei ${ }^{1 *}$ (D
}

\begin{abstract}
Background: Pulpitis is a common dental disease characterized by sustained inflammation and impaired pulp selfrepair. Mesenchymal stem cell-based minimally invasive vital pulp therapy (MSC-miVPT) is a potential treatment method, but its application is limited by the difficulty in acquiring MSCs. We recently revealed the immunomodulatory effects of rat dental follicle stem cells (rDFSCs) on acute lung injury. The present study focused on the paracrine effects of rDFSCs on the inflammation and regeneration of rat injured dental pulp to detect whether DFSCs are a potential candidate for MSC-miVPT.

Methods: Conditioned medium from rDFSCs (rDFSC-CM) was applied to lipopolysaccharide (LPS)-induced inflammatory rat dental pulp cells (rDPCs). The inflammation and regeneration of rDPCs were detected by RT-qPCR, Western blotting, immunofluorescence staining, Cell Counting Kit-8 (CCK-8) assay, flow cytometry, wound-healing assay, and Masson's staining. The effects of rDFSC-CM on inflamed rat dental pulp were further evaluated by hematoxylin-eosin and immunohistochemical staining.
\end{abstract}

Results: rDFSC-CM downregulated the ERK1/2 and NF-KB signaling pathways, which resulted in suppression of the expression of IL-1 $\beta, I L-6$, and TNF- $\alpha$ and promotion of the expression of IL-4 and TGF- $\beta$, and these findings lead to the attenuation of rDPC inflammation. rDFSC-CM enhanced the in vitro proliferation, migration, and odontogenic differentiation of inflammatory rDPCs and their in vivo ectopic dentinogenesis. Furthermore, rDFSC-CM inhibited inflammatory cell infiltration in rat pulpitis and triggered Runx2 expression in some of the odontoblast-like cells surrounding the injured site, and these effects were conducive to the repair of inflamed dental pulp.

Conclusions: rDFSC-CM exhibits therapeutic potential by rescuing the regeneration of the inflamed rat dental pulp through an immunomodulatory mechanism, indicating the application prospects of DFSCs in biological regenerative endodontics.

Keywords: Dental follicle stem cells, Immunomodulation, Paracrine effect, Pulpitis, Regenerative endodontics

\footnotetext{
*Correspondence: xqyu@scu.edu.cn; weixi@mail.sysu.edu.cn

${ }^{+}$Hong Hong and Xiaochuan Chen contributed equally to this work.

${ }^{3}$ Key Laboratory of Green Chemistry and Technology, Ministry of Education,

College of Chemistry, Sichuan University, Chengdu 610064, People's Republic of China

${ }^{1}$ Hospital of Stomatology, Guanghua School of Stomatology, Guangdong

Provincial Key Laboratory of Stomatology, Sun Yat-sen University, Guangzhou 510055, People's Republic of China

Full list of author information is available at the end of the article
}

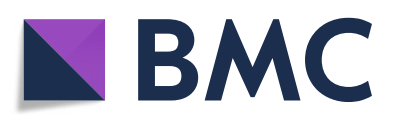

( ) The Author(s). 2020 Open Access This article is licensed under a Creative Commons Attribution 4.0 International License, which permits use, sharing, adaptation, distribution and reproduction in any medium or format, as long as you give appropriate credit to the original author(s) and the source, provide a link to the Creative Commons licence, and indicate if changes were made. The images or other third party material in this article are included in the article's Creative Commons licence, unless indicated otherwise in a credit line to the material. If material is not included in the article's Creative Commons licence and your intended use is not permitted by statutory regulation or exceeds the permitted use, you will need to obtain permission directly from the copyright holder. To view a copy of this licence, visit http://creativecommons.org/licenses/by/4.0/. The Creative Commons Public Domain Dedication waiver (http://creativecommons.org/publicdomain/zero/1.0/) applies to the data made available in this article, unless otherwise stated in a credit line to the data. 


\section{Background}

Dental pulp inflammation, which is also called pulpitis, is an inflammatory dental disease that causes the destruction of pulp tissues and eventually results in functional loss of the pulp. As bacteria and their toxic components penetrate into the pulp, inflammatory responses from resident cells, including dental pulp cells (DPCs), macrophages, and other immune cells, are initiated to eliminate invading microbes [1]. However, these antimicrobial activities allow the easy propagation of sustained inflammation, which is enormously destructive to the vital pulp and ultimately leads to tissue necrosis and prevention of innate selfrepair of the pulp [2-4]. Hence, the attenuation of excessive inflammation and the preservation of pulp vitality have been the most substantial challenges in modern endodontics. True innovation in the development of novel minimally invasive biotherapies for vital pulp preservation is critically needed.

Mesenchymal stem cells (MSCs) affect neighboring immune cells through direct cell-to-cell contact and/or various paracrine factors, such as indoleamine 2,3-dioxygenase (IDO), prostaglandin E2 (PGE2), TGF- $\beta$, and hepatocyte growth factor (HGF) [5-8]. On the one hand, MSCs exert immunosuppressive effects by suppressing the secretion of proinflammatory factors while increasing the expression of anti-inflammatory mediators of immune cells $[9,10]$, and on the other hand, MSCs regulate immune responses by eliciting the reprogramming of macrophages, suppressing the activation of $B$ and $\mathrm{T}$ cells, and facilitating the proliferation of Treg cells $[6,7,11,12]$. Based on their immunomodulatory capacities, MSCs are prospective candidates for use in cellbased therapies for various immune and inflammatory diseases [13-15], but the application of these therapies is limited by difficulty in acquiring MSCs.

The development of therapeutic applications for dental MSCs offers significant potential. The opportunity to isolate these cells from extracted teeth provides a ready source of dental MSCs, which eliminates the difficulty associated with their acquisition. Our previous study [16] showed that conditioned medium (CM) from rat dental follicle stem cells (rDFSCs), which are a type of dental MSCs, can effectively alleviate acute lung injury by downregulating the expression of proinflammatory cytokines and reprogramming macrophages toward the anti-inflammatory M2 phenotype. Protein arrays have revealed that $\mathrm{rDFSC}-\mathrm{CM}$ is rich in numerous bioactive factors. Herein, we hypothesized that rDFSC-CM is also a potential option for ameliorating pulp inflammation and facilitating tissue regeneration due to its immunomodulatory effects. In the present study, we investigated the immunomodulatory effects of rDFSC-CM on lipopolysaccharide (LPS)-induced inflammatory rat dental pulp cells (rDPCs) and pulpitis model rats. Furthermore, we explored the effects of rDFSC-CM on the regeneration capacity of inflammatory rDPCs in vitro and the self-repair of injured dental pulp tissue in vivo.

\section{Methods \\ Preparation of rDFSC-CM}

Sprague-Dawley (S-D) rats were obtained from the Laboratory Animal Center at Sun Yat-sen University, and dental follicle tissues were isolated at postnatal day 7, minced into small pieces, and digested in $\alpha$-minimum essential medium ( $\alpha$ MEM, Gibco, USA) supplemented with $3 \mathrm{mg} / \mathrm{mL}$ collagenase I and $4 \mathrm{mg} / \mathrm{mL}$ dispase II (Sigma-Aldrich, USA) at $37^{\circ} \mathrm{C}$ for $30 \mathrm{~min}$. The explants were then cultured in $\alpha M E M$ containing $20 \%$ fetal bovine serum (Gibco, USA), $100 \mathrm{U} / \mathrm{mL}$ penicillin, and $100 \mathrm{mg} / \mathrm{mL}$ streptomycin (Gibco, USA) at $37{ }^{\circ} \mathrm{C}$ in a humidified atmosphere with $5 \% \mathrm{CO}_{2}$. Once they reached $90 \%$ confluence, the cells were passaged at a 1:3 ratio, and cells from passages 3 to 5 were used in the experiments. When cells reached $70 \%$ confluence, the CM was collected after a 24$\mathrm{h}$ interval by exchanging the complete medium with fresh serum-free medium. The CM was centrifuged at $1000 \times g$ for $5 \mathrm{~min}$ and filtered through a $0.22-\mu \mathrm{m}$ strainer, and the culture supernatant was then stored at $-80^{\circ} \mathrm{C}$. To prepare the rDFSC-CM, the obtained medium was diluted $50 \%$ with an equal volume of $\alpha M E M$.

\section{Isolation and culture of rDPCs}

For the isolation of rDPCs, 5-week-old S-D rats were obtained from the Laboratory Animal Center at Sun Yatsen University. After intraperitoneal anesthesia with $10 \%$ chloral hydrate, the maxilla and mandible were separated, and the dental pulp tissues of the incisors were transferred to an $8-\mathrm{cm}^{2}$ culture dish and washed with phosphate-buffered saline (PBS, Sigma-Aldrich, USA) containing $2 \%$ penicillin-streptomycin (Sigma-Aldrich, USA). The minced pulp tissue was digested with $3 \mathrm{mg} /$ $\mathrm{mL}$ collagenase I and $4 \mathrm{mg} / \mathrm{mL}$ dispase II at $37^{\circ} \mathrm{C}$ for 30 min. The cells were cultivated in $\alpha$ MEM containing $20 \%$ FBS and $2 \%$ penicillin-streptomycin in a T25 cell culture flask at $37^{\circ} \mathrm{C}$ in an atmosphere with $5 \% \mathrm{CO}_{2}$. Cells from passages 3 to 5 were used in the experiments.

\section{Immunofluorescence staining of vimentin and cytokeratin in rDFSCs and rDPCs}

Immunofluorescence staining was performed according to standard protocols. In brief, the cells $\left(2 \times 10^{3}\right.$ cells/ well) were plated in 12-well plates (Corning, USA) and cultured for $24 \mathrm{~h}$. The media were then removed, and the cells were fixed with $4 \%$ paraformaldehyde (SigmaAldrich, USA) for $15 \mathrm{~min}$, permeabilized with $0.1 \%$ Triton X-100 (Sigma-Aldrich, USA) for $15 \mathrm{~min}$, and incubated with $10 \%$ donkey serum for $30 \mathrm{~min}$ at room temperature. The plates were then incubated with anti- 
vimentin antibody (Abcam, USA) at 1:200 dilution and anti-cytokeratin-14 antibody (Affinity, China) at 1:100 dilution overnight at $4{ }^{\circ} \mathrm{C}$. Alexa Fluor 488 donkey antirabbit IgG and Alexa Fluor 594 donkey anti-rabbit IgG (Life Technologies, USA; 1:400) were used as the secondary antibodies. The samples were scanned and photographed under a Panoramic MIDI slide scanner (3DHISTECH, Hungary).

\section{Flow cytometric analysis of surface markers of rDFSCs and rDPCs}

The phenotype of rDFSCs and rDPCs was identified by flow cytometric analysis. The MSC phenotyping cocktail comprised both positive (CD29-FITC, CD44/CD90-PE, $\mathrm{BD}$ Bioscience, USA) and negative (CD34-PE, CD45FITC, BD Bioscience, USA) fluorochrome-conjugated monoclonal antibodies. IgG1-FITC and IgG1-PE (BD Bioscience, USA) were used as isotype controls. Thirdpassage rDFSCs and rDPCs were suspended to $5 \times 10^{5}$ cells $/ \mathrm{mL}$ in PBS solution, stained with different antibodies for $30 \mathrm{~min}$ at $4{ }^{\circ} \mathrm{C}$, washed with PBS, resuspended in FACS buffer, and analyzed using a $\mathrm{MOFlo}^{\mathrm{m}}$ highperformance cell sorter (Beckman Coulter, USA).

\section{Evaluation of osteogenic and adipogenic capabilities of rDFSCs and rDPCs}

The cells $\left(2 \times 10^{5}\right.$ cells/well $)$ were loaded in six-well plates (Corning, USA). Once the cells reached $80 \%$ confluence, the medium was changed to commercial osteogenic medium (Cyagen Biosciences, China) or adipogenic medium (Cyagen Biosciences, China). After 14 days of induction, the cells were fixed in $4 \%$ paraformaldehyde (Sigma-Aldrich, USA) for $30 \mathrm{~min}$ and then subjected to Alizarin Red staining (Cyagen Biosciences, China) to reveal calcium depositions or Oil Red O staining (Cyagen Biosciences, China) for the observation of lipid droplets. The cells were imaged with a Fluorescence Inversion Microscope System (Carl Zeiss, Germany).

\section{LPS-induced inflammatory rDPCs}

The rDPCs $\left(1 \times 10^{5}\right.$ cells/well $)$ were seeded in six-well plates and cultivated in $\alpha M E M$ containing 10\% FBS and $2 \%$ penicillin-streptomycin. When the cells reached $70 \%$ confluence, the culture medium was changed to $\alpha M E M$ with LPS $(0.5 \mathrm{mg} / \mathrm{L}$, Escherichia coli, Sigma-Aldrich, USA). Cells that were not stimulated with LPS were used as a control.

\section{Real-time quantitative PCR}

The gene expression of inflammatory cytokines in rDPCs was investigated by real-time quantitative PCR using SYBR Green Mix (Roche, Germany). rDPCs were treated with $\alpha M E M$ or rDFSC-CM for 3, 6, and $9 \mathrm{~h}$, and total RNA was isolated from the inflammatory rDPCs using
TRIzol (Invitrogen, USA). First-stand cDNA was synthesized from $2 \mu \mathrm{g}$ of total RNA. The PCR primers were synthesized by Invitrogen (Life Technologies, USA), and their sequences are listed in Table 1 . The data were acquired and analyzed using a LightCycler 480 system.

\section{Western blot analysis}

The cells were cultured in $\alpha \mathrm{MEM}$ or rDFSC-CM with $0.5 \mathrm{mg} / \mathrm{L}$ LPS for $0,15,30,60$, and $120 \mathrm{~min}$, and protein was then collected by lysis with phosphatase inhibitor and protease inhibitor (Thermo Fisher Scientific, USA). The protein contents were quantified using a bicinchoninic acid protein assay kit (Biocolors, China). Thirty micrograms of proteins was separated on sodium dodecyl sulfate-polyacrylamide gels and transferred to nitrocellulose membranes (Millipore, USA). The membranes were probed with the following primary antibodies overnight at $4{ }^{\circ} \mathrm{C}$ : anti-p-p38 MAPK, anti-p38 MAPK, anti-p-ERK 1/2, anti-ERK1/2, anti-p-SAPK/JNK, anti-SAPK/JNK, anti-p-p65 NF- $\kappa B$, anti-p65 NF-кB (1:1000, Cell Signaling Technology, USA), and anti-vinculin (1:5000, Abcam, USA). The membranes were subsequently washed for $30 \mathrm{~min}$ and incubated with horseradish peroxidase-conjugated secondary antibody (Cell Signaling Technology, USA) at 1:5000 dilution. The immunoreactive proteins were visualized by enhanced chemiluminescence (ECL; Millipore, USA), and the densities of the protein bands were quantified using ImageJ version 1.50i software (Bethesda, USA).

\section{Immunofluorescence analysis}

The subcellular location of NF-kB p65 in inflammatory rDPCs after treated with $\alpha$ MEM or rDFSC-CM for 60

Table 1 Primers for inflammatory cytokines used in the realtime quantitative PCR assay

\begin{tabular}{|c|c|c|}
\hline \multirow{2}{*}{$\frac{\text { Gene }}{I L-1 \beta}$} & \multicolumn{2}{|c|}{ Primer sequence } \\
\hline & Forward & CCCTGAACTCAACTGTGAAATAGCA \\
\hline & Reverse & CCCAAGTCAAGGGCTTGGAA \\
\hline \multirow[t]{2}{*}{ IL-6 } & Forward & ATTGTATGAACAGCGATGATGCAC \\
\hline & Reverse & CCAGGTAGAAACGGAACTCCAGA \\
\hline \multirow[t]{2}{*}{$T N F-a$} & Forward & TCAGTTCCATGGCCCAGAC \\
\hline & Reverse & GTTGTCTTTGAGATCCATGCCATT \\
\hline \multirow[t]{2}{*}{ IL-4 } & Forward & CAAGGAACACCACGGAGAAC \\
\hline & Reverse & CTCAGTGAGTTCAGACCGCT \\
\hline \multirow[t]{2}{*}{ TGF- $\beta$} & Forward & GAAGTCACCCGCGTGCTAATGG \\
\hline & Reverse & GTGTGTCCAGGCTCCAAATGTAGG \\
\hline \multirow[t]{2}{*}{ IL-10 } & Forward & GTGTGTCCAGGCTCCAAATGTAGG \\
\hline & Reverse & CAAGGCTTGGCAACCCAAGTA \\
\hline \multirow[t]{2}{*}{$\beta$-Actin } & Forward & CCTCTTTGCATGTCTCACTC \\
\hline & Reverse & AATGTCACGCACGATTTCC \\
\hline
\end{tabular}


min was examined by immunofluorescence staining. Briefly, rDPCs were fixed in $4 \%$ formaldehyde solution for $15 \mathrm{~min}$, permeabilized with $0.1 \%$ Triton X-100 for $15 \mathrm{~min}$, and incubated with $10 \%$ swine serum (ImmunoReagents, USA) for $1 \mathrm{~h}$ at room temperature. The samples were stained with anti-NF- $\mathrm{kB}$ p65 antibody (Cell Signaling Technology, USA) at 1:400 dilution overnight at $4{ }^{\circ} \mathrm{C}$ and then with Alexa Fluor 546-labeled secondary antibody (Invitrogen, USA) at 1:200 dilution for $2 \mathrm{~h}$ at room temperature. The samples were mounted and photographed under a fluorescence microscope (Carl Zeiss, Germany).

\section{Cell proliferation assay}

rDPCs $\left(3 \times 10^{3}\right.$ cells/well $)$ were cultured in 96-well plates for $24 \mathrm{~h}$ and then cultured in $\alpha \mathrm{MEM}$ or rDFSC-CM with or without LPS $(0.5 \mathrm{mg} / \mathrm{L})$ for 1,2 , and 3 days. The proliferation of the cells was evaluated using the Cell Counting Kit- 8 assay (CCK-8, Beyotime, China). The absorbance at a wavelength of $450 \mathrm{~nm}$ was determined.

\section{Assessment of the cell cycle and apoptosis by flow cytometry}

rDPCs were cultured in $\alpha \mathrm{MEM}$ or $\mathrm{rDFSC}-\mathrm{CM}$ with or without $0.5 \mathrm{mg} / \mathrm{L}$ LPS for $24 \mathrm{~h}$, harvested by trypsinization, and fixed with $70 \%$ cold ethanol for $1 \mathrm{~h}$ on ice. After washing, the cells were incubated with Annexin V/ 7-aminoactinomycin D (7-AAD, BD Biosciences, USA) for $30 \mathrm{~min}$ at $4{ }^{\circ} \mathrm{C}$ in the dark. Cell apoptosis and the cell cycle distribution were analyzed using a FACSCalibur flow cytometer (BD Biosciences, USA) and Cell Quest version 3.1 software (BD Biosciences, USA) according to the manufacturer's instructions.

\section{Migration assay}

Wound-healing and Transwell migration assays were employed to assess the migration capacity of rDPCs after $\alpha M E M$ or rDFSC-CM treatment. For the wound-healing assay, rDPCs $\left(2 \times 10^{5}\right.$ cells/well $)$ were seeded in 24-well plates in $\alpha$ MEM with $10 \%$ FBS for $24 \mathrm{~h}$ to obtain a monolayer. After the cells reached $90 \%$ confluence, a 4 $\mu \mathrm{m}$-wide wound was made with a sterile pipette tip on the monolayer. The culture was replenished with $\alpha M E M$ or rDFSC-CM with or without $0.5 \mathrm{mg} / \mathrm{L}$ LPS. The cells were incubated at $37^{\circ} \mathrm{C}$ in an atmosphere with $5 \% \mathrm{CO}_{2}$ for $24 \mathrm{~h}$. The migrated cells were captured under an inverted light microscope (Carl Zeiss, Germany). The Transwell migration assay was performed using Transwell chambers and inserts with $8-\mu \mathrm{m}$ pores (Corning, USA). Suspended cells (at a density of $2 \times 10^{5}$ cells $/ \mathrm{mL}$ in $100 \mu \mathrm{L}$ of FBS-free medium) were seeded into the upper chambers. The lower chambers contained $\alpha M E M$ or rDFSC-CM with or without $0.5 \mathrm{mg} / \mathrm{L}$ LPS. After $24 \mathrm{~h}$ of incubation at $37^{\circ} \mathrm{C}$ and $5 \% \mathrm{CO}_{2}$, the cells were fixed with $4 \%$ paraformaldehyde (Beyotime, China) for $15 \mathrm{~min}$ and stained with a $1 \%$ crystal violet solution (Beyotime, China) for $30 \mathrm{~min}$. The nonmigrated cells on the upper membrane were removed using cotton swabs. The cells that had migrated through the membrane were captured and counted under an inverted light microscope (Carl Zeiss, Germany).

\section{Mineralization assay}

A total of 50,000 rDPCs were seeded into each well of six-well plates containing $\alpha M E M$ with $10 \%$ FBS and incubated for $24 \mathrm{~h}$. The culture medium was then changed to odontogenesis-inducing medium containing $0.5 \mathrm{mg} / \mathrm{L}$ LPS with or without rDFSC-CM. For Alizarin Red staining, the cells were fixed at day 7 , stained with $1 \%$ Alizarin Red S (Sigma-Aldrich, USA) at room temperature for $1 \mathrm{~h}$, and washed twice with PBS. The mineralized nodules were observed and photographed under a stereomicroscope (Olympus, Japan). The expression of the odontogenic genes alkaline phosphatase (ALP), dentin sialophosphoprotein (DSPP), Runt-related transcription factor 2 (Runx2), bone sialoprotein (BSP), and dentin matrix acidic phosphoprotein 1 (DMP1) was evaluated by real-time quantitative PCR using the primer sequences listed in Table 2.

\section{Detection of dentin collagen fiber synthesis in vivo}

To detect the effects of rDFSC-CM on the odontogenic differentiation of rDPCs in vivo, cells $\left(1 \times 10^{6}\right.$ cells $\left./ \mathrm{mL}\right)$ were loaded onto hydroxyapatite/tricalcium phosphate scaffolds (HA/TCP, Engineering Research Centre in Biomaterials, Sichuan University, China), which were assigned to four experimental groups: bare scaffold, aMEM-treated cell-loaded scaffold, $\alpha M E M / L P S-t r e a t e d$ cell-loaded scaffold, and rDFSC-CM/LPS-treated cellloaded scaffold. The samples were transplanted

Table 2 Primers for odontogenic differentiation markers used in the real-time quantitative PCR assay

\begin{tabular}{lll}
\hline Gene & Primer sequence & \\
\hline ALP & Forward & AACGTGGCCAAGAACATCATCA \\
& Reverse & TGTCCATCTCCAGCCGTGTC \\
DSPP & Forward & GGTGCTCATCTCCCATTGTGA \\
& Reverse & CAGGTAGCAGCGTGTGAAAGC \\
Runx2 & Forward & CAGTAGCAAACCGAAACAC \\
& Reverse & CACACACAGACAATAAATAGCA \\
BSP & Forward & TGTGGAATGGTGCTACGGTCTC \\
& Reverse & GATCAACAGCCCTGATTACGATG \\
DMP1 & Forward & GAGCGATCGAGGCCATACC \\
& Reverse & CTCGTGATCCCCTTAGATTCTC \\
B-Actin & Forward & CCTCTTGCATGTCTCACTC \\
& Reverse & AATGTCACGCACGATTCC \\
\hline
\end{tabular}


subcutaneously into the backs of nude mice obtained from the Laboratory Animal Center at Sun Yat-sen University. The protocol was approved by the University Ethics Committee of the ZSSOM on Laboratory Animal Care (No. 2017-194). The mice were sacrificed at 8 weeks postimplantation. The samples were separated, fixed in $4 \%$ paraformaldehyde (Beyotime, China) solution for 24 $\mathrm{h}$, and decalcified in commercial demineralization liquid (Beyotime, China) for 2 weeks. The samples were subsequently embedded in paraffin and cut into 5 - $\mu \mathrm{m}$-thick sections. Masson's staining was applied to assess the dentin collagen fibers according to our previously published protocols [17]. The images were captured using an inverted light microscope. The expression of the above-described odontogenic proteins was evaluated by Western blotting. Primary antibodies against the following proteins were used: ALP (Abcam, USA; 1:1000 dilution), Runx2 (Abcam, USA; 1:1000 dilution), DSPP (Santa Cruz, USA; 1:2000 dilution), and vinculin (Abcam, USA; 1:5000 dilution). The densities of the protein bands were quantified using ImageJ version $1.50 \mathrm{i}$ software (Bethesda, USA).

\section{Rat pulpitis induction and rDFSC-CM administration}

Eight-week-old male S-D rats weighing $240-280 \mathrm{~g}(N=$ 30) were purchased from the Laboratory Animal Center at Sun Yat-sen University. The experiments were approved by the University Ethics Committee of the ZSSOM on Laboratory Animal Care (No. 2017-195). After the induction of anesthesia through the intraperitoneal injection of $10 \%$ chloral hydrate, the rats underwent drilling of the maxillary first molar on the occlusal surface using a high-speed handpiece and a round diamond bur (Shofu, Canada). Coronal pupal exposure was then confirmed using a sterile size $10 \mathrm{~K}$-file that was sequentially increased to a size $40 \mathrm{~K}$-file. After hemostasis was achieved, the injured site was directly capped with an aseptic gelatin sponge soaked in rDFSC-CM or aMEM with $10 \mathrm{mg} / \mathrm{mL}$ LPS and then sealed with lightcured glass ionomer cement (3M, USA). Twenty-four hours later, half of the animals were sacrificed, and their teeth were extracted, fixed, decalcified, embedded in paraffin, and cut into 5 - $\mu \mathrm{m}$-thick sections as described above. Hematoxylin-eosin (HE) staining was used for evaluation of inflammatory infiltration. The rest of the rats were sacrificed 7 days later, and their teeth were carefully extracted for immunohistochemistry with antiRunx2 (1:200, Abcam, USA). Images were captured with an inverted light microscope.

\section{Statistical analysis}

The data are presented as the means \pm standard deviations (SDs) from at least three independent experiments and were analyzed using GraphPad Prism version 6.0 software (GraphPad, Inc., USA). Student's $t$ test was selected for pairwise comparisons, and one-way analysis of variance (ANOVA) was used for multiple comparisons. Differences with $P<0.05$ were considered statistically significant.

\section{Results}

\section{Identification of rDFSCs and rDPCs}

DFSCs and rDPCs were successfully isolated from rat dental follicle or dental pulp tissues (Fig. 1a, f), and immunofluorescence analysis showed that rDFSCs and rDPCs were both positive for the MSC marker vimentin (Fig. 1b, g) and negative for the epithelial marker cytokeratin (Fig. 1c, h). A flow cytometric analysis showed that the rDFSCs expressed high levels of the MSC markers CD29 (99.84\%), CD44 (99.89\%), and CD90 (99.97\%) and were negative for the hematopoietic markers CD34 $(0.60 \%)$ and CD45 (0.65\%) (Fig. 1k-q). rDPCs also expressed high levels of the MSC markers CD29 (99.53\%), CD44 (98.50\%), and CD90 (93.01\%) and were negative for CD34 (0.98\%) and CD45 (1.04\%) (Fig. 1r-x). In addition, after induction in osteogenic medium for 14 days, both rDFSCs and rDPCs formed mineralized nodules that were visualized by Alizarin Red staining (Fig. 1d, i). After culture in adipogenic medium for 14 days, both rDFSCs and rDPCs formed lipid droplets, as visualized by Oil Red O staining (Fig. 1e, j). These results demonstrated the stem cell characteristics and multipotent differentiation abilities of rDFSCs and rDPCs.

\section{rDFSC-CM attenuated inflammation in LPS-stimulated rDPCs}

The mRNA levels of the proinflammatory cytokines IL-1 $\beta$, IL-6, and TNF- $\alpha$ were significantly higher in rDPCs exposed to $0.5 \mathrm{mg} / \mathrm{L}$ LPS for 3,6 , and $9 \mathrm{~h}$ than in the control group. However, treatment with rDFSC-CM downregulated the expression of proinflammatory cytokines in LPSstimulated rDPCs (Fig. 2a-c). Furthermore, treatment with rDFSC-CM for $3 \mathrm{~h}$ promoted the expression of the anti-inflammatory cytokines IL- 4 and TGF- $\beta$ in LPSstimulated rDPCs, although the level of IL-10 was downregulated after $9 \mathrm{~h}$ of treatment (Fig. $2 \mathrm{~d}-\mathrm{f}$ ). These results demonstrated that rDFSC-CM could ameliorate LPSinduced inflammation in rDPCs.

The ERK1/2 and NF-KB signaling pathways were involved in rDFSC-CM-mediated anti-inflammatory effects on LPSstimulated rDPCs

Stimulation with LPS for 15 to $120 \mathrm{~min}$ induced the phosphorylation of ERK1/2 in $\mathrm{rDPCs}$ in a timedependent manner, and ERK1/2 phosphorylation was significantly suppressed by $\mathrm{rDFSC}-\mathrm{CM}$ treatment (Fig. 3a, b). In contrast, the phosphorylation of P38 or SAPK/JNK induced by either LPS stimulation or rDFSC- 

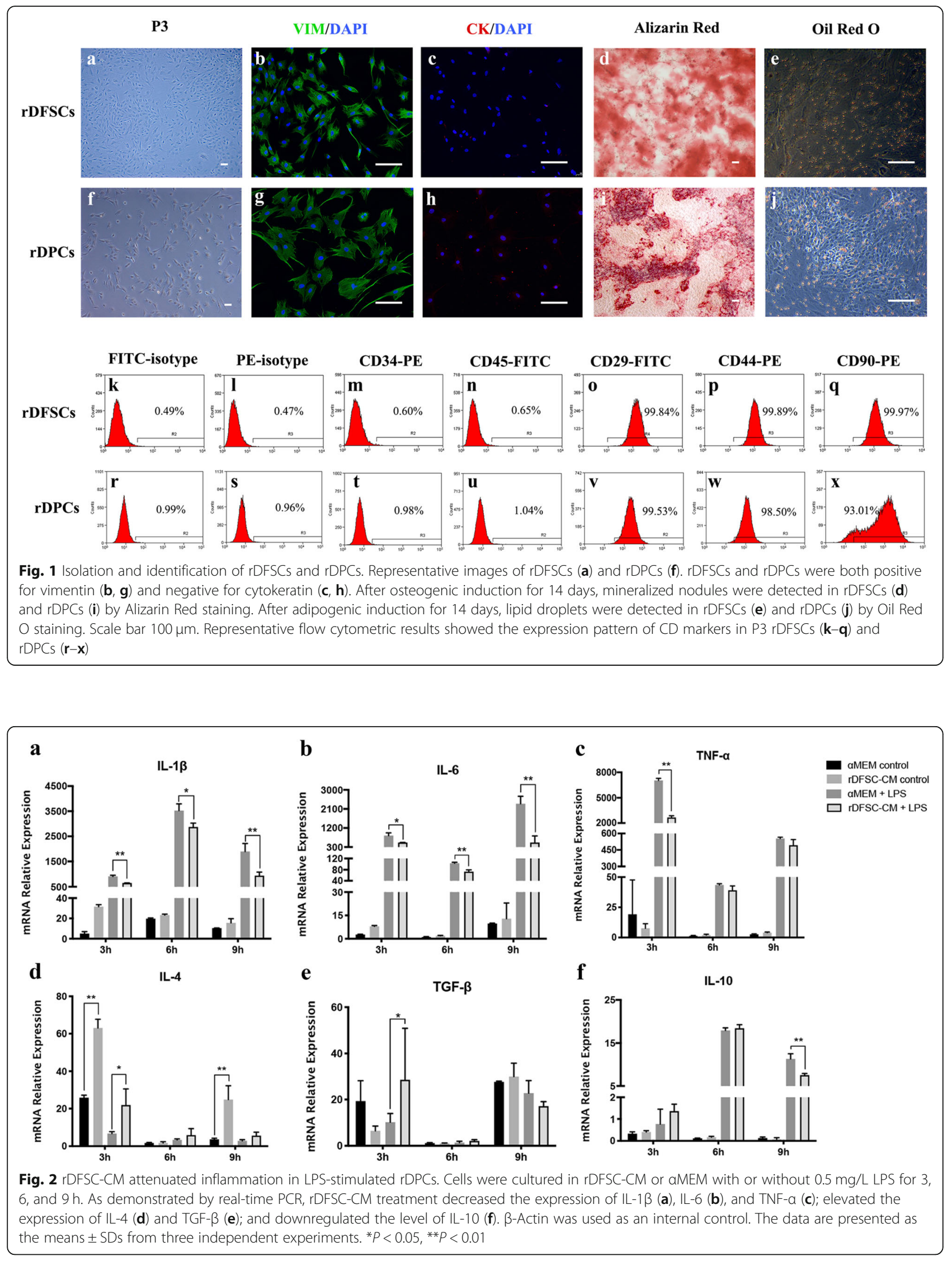


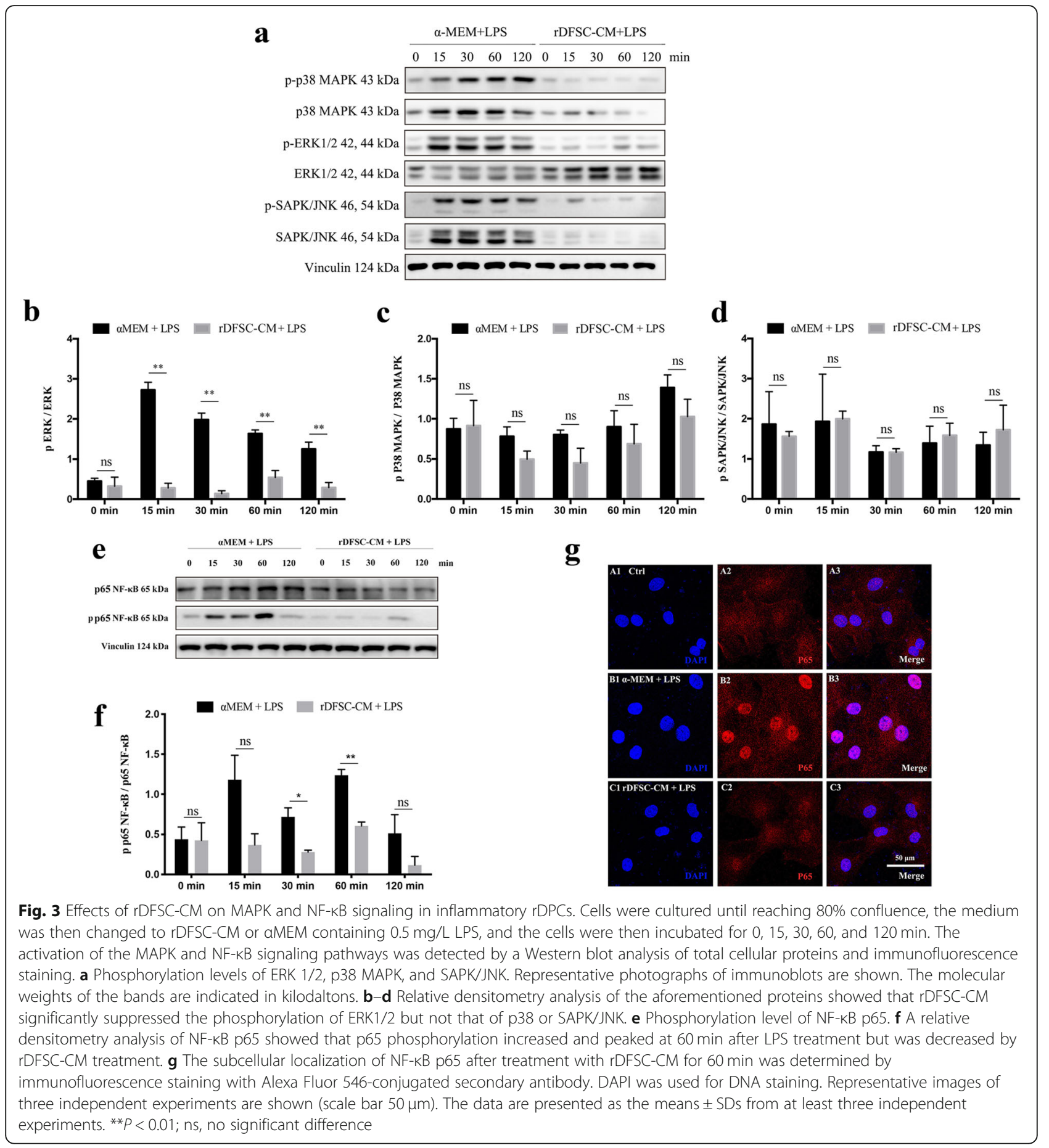

CM treatment differed little (Fig. 3a, c, d). The phosphorylation of p65 was increased and peaked at $60 \mathrm{~min}$ after LPS treatment but decreased after rDFSC-CM treatment (Fig. 3e, f). This finding was further confirmed by immunofluorescent staining, which showed that the expression of nuclear p65 was increased by LPS stimulation but reduced by rDFSC-CM treatment for $60 \mathrm{~min}$ (Fig. 3g).
Effects of rDFSC-CM on the proliferation, apoptosis, cell cycle, and migration of LPS-stimulated rDPCs

As shown in Fig. 4a, rDFSC-CM treatment for 1 to 3 days significantly increased the proliferation of rDPCs, and treatment for $24 \mathrm{~h}$ downregulated the apoptosis of these cells (Fig. 4b-f). Furthermore, rDFSC-CM treatment for $24 \mathrm{~h}$ significantly decreased the proportion of 


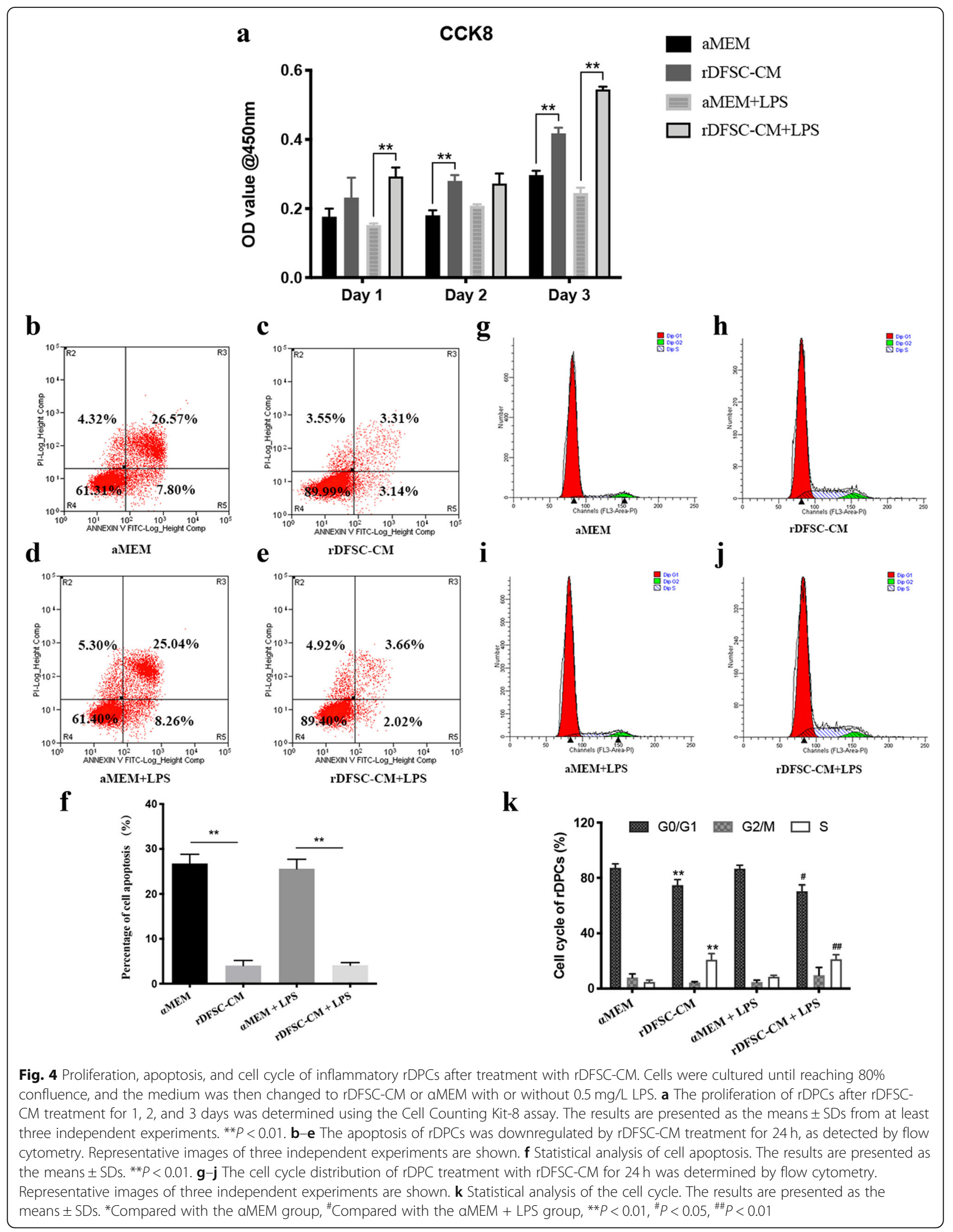


rDPCs at the G0/G1 phase and increased that at S phase (Fig. 4g-k). Cell migration was decreased by LPS stimulation for $24 \mathrm{~h}$, but significantly increased by rDFSC-CM treatment (Fig. 5a-c).

rDFSC-CM facilitated the odontogenic differentiation and ectopic dentinogenesis of inflammatory rDPCs

To explore the impact of rDFSC-CM on the odontogenic differentiation of rDPCs under inflammatory conditions, the cells were cultured in LPS-containing odontogenic medium with or without rDFSC-CM. After 7 days of induction, markedly improved mineralized matrix deposition was observed after rDFSC-CM treatment compared with $\alpha M E M$ treatment, as demonstrated by Alizarin Red S staining (Fig. 6A-E). Real-time PCR revealed that the expression of the odontogenesis-related genes ALP, DSPP, Runx2, BSP, and $D M P 1$ was increased by $\mathrm{rDFSC}-\mathrm{CM}$ treatment compared with $\alpha \mathrm{MEM}$ treatment (Fig. $6 \mathrm{~F}-\mathrm{K}$ ).

We subsequently evaluated the effects of rDFSC-CM on the ectopic dentinogenesis of rDPCs in vivo. HA/ TCP scaffolds were used to load rDFSC-CM-treated rDPCs, and the scaffolds were implanted subcutaneously into the backs of nude mice and maintained in the mice

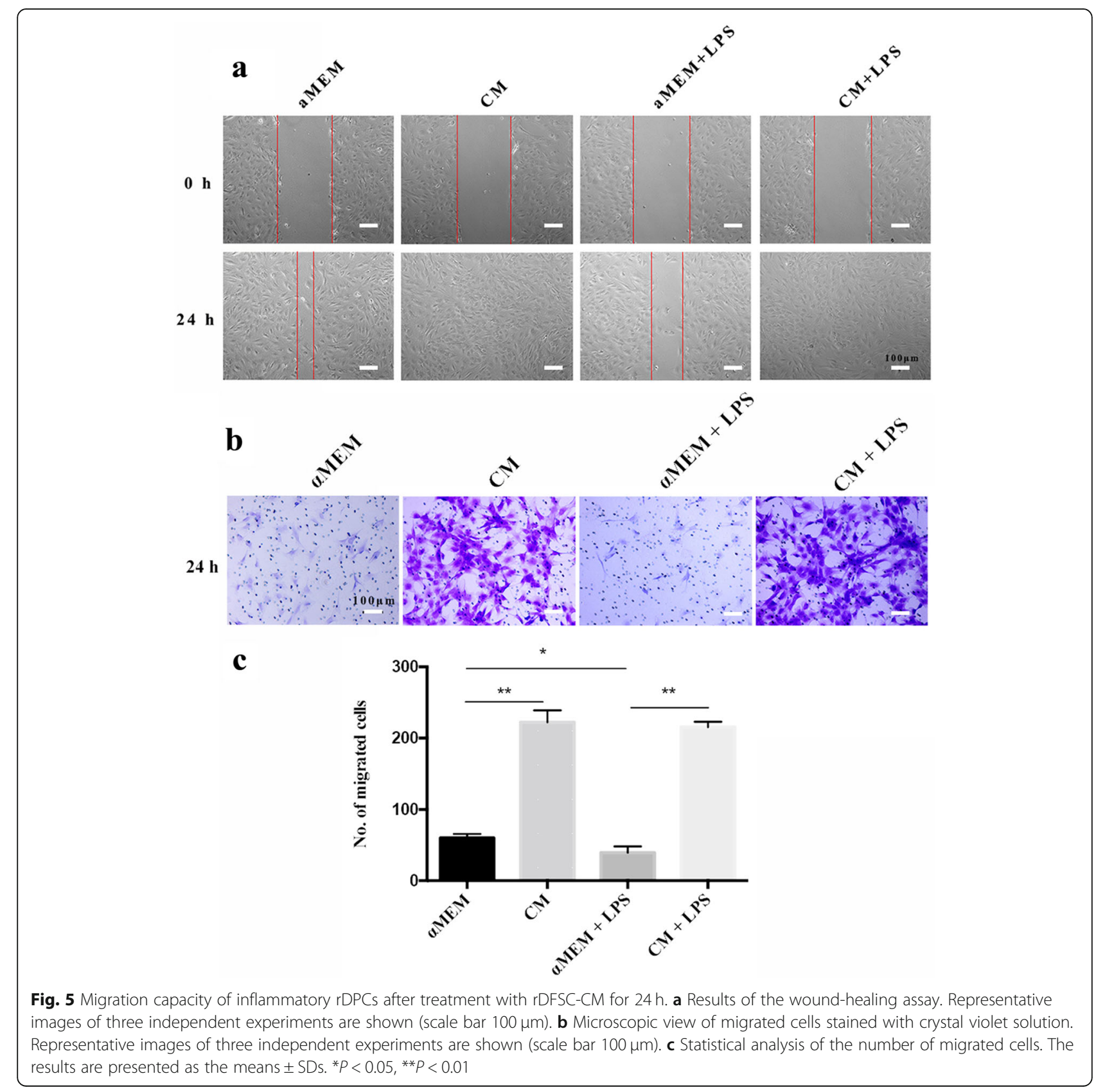






for 8 weeks. As demonstrated by Masson's staining, the production of collagen fibers in rDPCs was decreased under inflammatory conditions but increased by rDFSC-
CM treatment (Fig. 6L-O). A Western blot analysis also revealed a significant increase in Runx2 expression in inflammatory rDPCs treated with rDFSC-CM. 
Furthermore, the ALP and DSPP protein levels were also increased in the rDFSC-CM group, although the differences were not statistically significant (Fig. 6P, Q).

\section{rDFSC-CM suppressed inflammatory infiltration and promoted Runx2 expression in rat pulpitis tissue}

To study whether rDFSC-CM can reduce inflammatory infiltration and promote the repair of dental pulp tissue after injury, an experimental pulpitis model was constructed in rats by using $10 \mathrm{mg} / \mathrm{mL}$ LPS. HE staining revealed that $24 \mathrm{~h}$ of treatment resulted in typical inflammation, as evidenced by the infiltration of a large number of inflammatory cells (black arrows) in the coronal pulp and the dilatation of blood vessels in the radicular pulp, which indicated the successful induction of pulpitis (Fig. 7A, B). Intriguingly, slight inflammatory infiltration or capillary dilatation was observed in the pulp capped with rDFSC-CM for $24 \mathrm{~h}$ (Fig. 7C). After 7 days of treatment with LPS, capillary dilatation was still observed (red arrows). A large number of inflammatory cells had infiltrated and were distributed diffusely, and few Runx2-positive cells observed (Fig. 7D, E). In contrast, rDFSC-CM treatment suppressed inflammatory cell infiltration and triggered Runx2 expression (yellow arrows) in some of the odontoblast-like cells near the injured site (Fig. 7F).

\section{Discussion}

DPCs, the most abundant cell types in dental pulp, are the main cells that function in host defenses and tissue regeneration in the pulp-dentin complex [18]. When exposed to bacteria and/or their toxic components, DPCs can recognize invading bacteria via their expression of a variety of pattern recognition receptors $[1,19-21]$ and induce an innate immune response by expressing antimicrobial peptides (AMPs) and secreting various inflammatory cytokines, such as TNF- $\alpha$, IL-6, IL- 8, IL- $1 \alpha$, CCL7, CCL26, and CXCL11 [19, 22-26], and these effects lead to the recruitment of macrophages, neutrophils, and other immune cells and initiation of the early inflammatory response to eliminate invading microbes [1]. Moreover, DPCs subsequently migrate to the injured site, where they differentiate into odontoblast-like cells to synthesize reparative dentin, initiating repair and regeneration [27-30]. However, antibacterial activities easily induce the inflammatory cascade and thereby

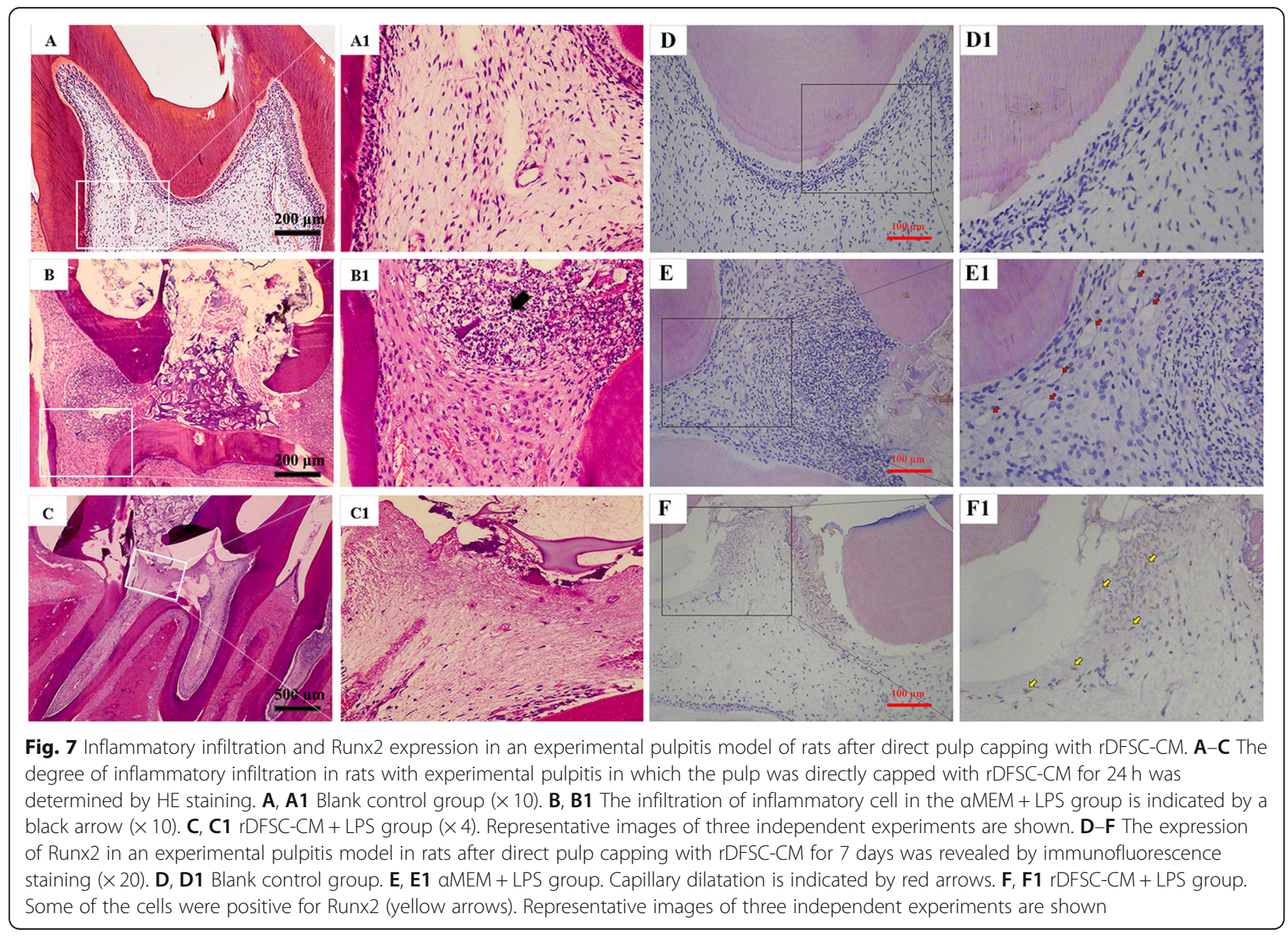


propagate sustained inflammation [2-4], which not only irreversibly damages vital pulp tissue but also actively impedes the repair responses of DPCs, and these effects eventually lead to total necrosis of the pulp [1, 24]. Hence, attenuation of inflammation is a prerequisite for the initiation of pulp healing and regeneration. The vital importance of DPCs in the dynamic interplay between inflammation and regeneration should be brought to the forefront.

DFSCs, which can be easily obtained from the dental follicle of impacted third molars, exhibit enhanced proliferation and differentiation capacities and exert a stronger immunomodulatory effect on lymphocytes and Treg cells than other dental MSC types, such as stem cells from human exfoliated deciduous teeth (SHEDs) and DPSCs [31, 32]. Our previous study demonstrated that rDFSC-CM plays an immunomodulatory role in rat acute lung injury by suppressing the levels of proinflammatory cytokines and reprogramming of macrophages toward the antiinflammatory M2 phenotype [16]. During tooth development, the dental follicle encompasses the dental papilla (the precursor of dental pulp), and cells from both different tissues intimately involved, which allows the creation of specific local niches for tissue development. We found that the indirect coculture of DFSCs and dental papilla cells activates the expression of reprogramming markers and inhibits the apoptosis of dental papilla cells [33], which suggests that DFSC-CM optimizes the extracellular microenvironment to enhance the reprogramming capacity of other dental cells. Accordingly, we hypothesize that $\mathrm{rDFSC}-\mathrm{CM}$ is a prospective option for ameliorating the inflammatory state of the injured dental pulp and promoting pulp regeneration due to its immunomodulatory effects on rDPCs.

To verify this hypothesis, we first investigated the immunomodulatory effects of rDFSC-CM on inflammatory rDPCs. Consistent with a previous study [34], rDPCs showed a rapid response to LPS exposure and presented upregulated gene expression of IL-1 $\beta$, IL- 6 , and TNF- $\alpha$. rDFSC-CM treatment significantly downregulated the levels of these proinflammatory cytokines and increased the mRNA levels of the anti-inflammatory cytokines IL4 and TGF- $\beta$ in inflammatory rDPCs. In addition, rDFSC-CM significantly inhibited the phosphorylation of ERK1/2 and p65 and suppressed the nuclear translocation of $\mathrm{p} 65$, which indicated that rDFSC-CM regulated the expression of proinflammatory and antiinflammatory cytokines in rDPCs by inhibiting activation of the inflammatory MAPK and NF-кB signaling pathways. To further detect whether $\mathrm{PDFSC}-\mathrm{CM}$ can alleviate pulp inflammation in vivo, an experimental pulpitis model was generated in rats, and the model rats presented the diffuse infiltration of inflammatory cells in the pulp after 7 days of LPS treatment. When the pulp was capped with rDFSC-CM, however, the degree of pulpal inflammation subsided substantially, and only slight inflammatory cell infiltration or capillary dilatation observed. These in vitro and in vivo results indicated the immunomodulatory capacity of rDFSC-CM in alleviating the inflammatory responses of DPCs and injured dental pulp.

Injured dental pulp has an innate capacity for selfregeneration. However, sustained inflammation might cause an imbalance in the dynamic equilibrium of the dental pulp and suppress pulp regeneration mediated by DPCs [24]. In the present study, the reduced expression of proinflammatory cytokines in inflammatory rDPCs treated with rDFSC-CM was accompanied by increased cell proliferation and transformation from the G1/G0 to the $\mathrm{S}$ phase, which indicated that rDFSC-CM can expedite the cell cycle and thus accelerate cell proliferation. In addition, treatment with $\mathrm{rDFSC}-\mathrm{CM}$ significantly promoted the migration of inflammatory rDPCs but decreased cell apoptosis. These data indicated that the regenerative capacities of inflammatory rDPCs were improved. On the other hand, rDFSC-CM enhanced mineralized nodule formation and odontogenic gene expression in vitro and the ectopic dentin collagen fiber deposition of inflammatory rDPCs in vivo, and these findings indicate that rDFSC-CM exerts advantageous effects on the odontoblastic differentiation of inflammatory rDPCs via immunomodulatory pathways. A rat model of direct pulp capping provided further evidence of the repair and regeneration cascade in the inflamed pulp. rDFSC-CM treatment inhibited the infiltration of inflammatory cells and triggered the expression of the mineralized marker Runx2 in some of the odontoblastlike cells in proximity to the injured site. Taken together, these results demonstrate that $\mathrm{rDFSC}-\mathrm{CM}$ might help create an optimal microenvironment that favors tissue repair and regeneration due to its immunomodulatory effects on primary immune cells in the injured pulp, including rDPCs.

In our previous study, we characterized the soluble factors in $\mathrm{rDFSC}-\mathrm{CM}$ by protein array analysis and found that rDFSC-CM contains 42 proteins at levels that were at least 2-fold greater than those in the control group [16]. To identify the possible effective components, we performed a cluster analysis of these proteins and identified 26 factors that are known to exhibit functional properties that might be beneficial for the treatment of pulpitis (Table 3). TGF- $\beta 3$ and TSP-1 can reprogram macrophages into the antiinflammatory M2 phenotype [16], and TGF- $\beta 3$ also induces ectopic mineralization in DPCs to regulate their differentiation to odontoblasts [42]. FGF-2 effectively promotes the proliferation and odontogenic differentiation of DPCs under inflammatory 
Table 3 Differentially expressed ( $>$ 2-folds) soluble factors in rDFSC-CM compared with serum-free control medium identified by a protein array

\begin{tabular}{|c|c|c|}
\hline & Ratio & References \\
\hline \multicolumn{3}{|c|}{ Anti-inflammation } \\
\hline TSP-1 & 105.9 & {$[35]$} \\
\hline $\mathrm{ACTH}$ & 96.5 & {$[36]$} \\
\hline TRAIL & 23.0 & {$[37]$} \\
\hline AMPK-a1 & 10.4 & [38] \\
\hline FGF-2 & 3.1 & [39] \\
\hline \multicolumn{3}{|c|}{ Odonto/osteogenesis } \\
\hline OPN & 69.5 & {$[40]$} \\
\hline Leptin & 68.1 & [41] \\
\hline TGF- $\beta 3$ & 18.6 & {$[42]$} \\
\hline EGFR & 8.6 & [43] \\
\hline MMP-2 & 4.2 & [44] \\
\hline$\beta$-Catenin & 3.3 & {$[45]$} \\
\hline \multicolumn{3}{|c|}{ Angiogenesis } \\
\hline VEGF & 38.4 & {$[46]$} \\
\hline VEGF-C & 24.4 & {$[47]$} \\
\hline FGF-BP & 15.5 & {$[48]$} \\
\hline FSL-1 & 11.9 & [49] \\
\hline TIE-2 & 8.2 & {$[50]$} \\
\hline \multicolumn{3}{|c|}{ Neuroprotection } \\
\hline NGFR & 640.5 & [51] \\
\hline NRP-2 & 74.5 & {$[52]$} \\
\hline Orexin A & 42.7 & [53] \\
\hline MUSK & 24.4 & {$[54]$} \\
\hline GFR-a2 & 6.9 & {$[55]$} \\
\hline BDNF & 4.6 & {$[56]$} \\
\hline \multicolumn{3}{|c|}{ Pro-proliferation/anti-apoptosis } \\
\hline TIMP-1 & 87.5 & {$[57]$} \\
\hline TIMP-2 & 3.1 & {$[58]$} \\
\hline Ubiquitin & 17.9 & {$[59]$} \\
\hline CXCR-4 & 5.4 & [60] \\
\hline
\end{tabular}

conditions [61] and enhances the in vivo ectopic formation of dentin-like material of stem cells from inflamed dental pulp tissue [39]. OPN plays a nonredundant role in regulating the formation and mineralization of mouse dentin [40]. Leptin can induce angiogenesis, odontogenic differentiation, and mineralization in human DPCs [41]. VEGF promotes the in vitro angiogenesis of human DPCs through modulation of the expression of lysyl oxidase [46]. A specific distribution of NGFR was observed in the tooth buds and dental follicle [62]. NRP-2 not only functions as a receptor for semaphorins, which are a family of neural axon guidance factors, but also interacts with VEGFs [63]. Considering the multiple functions and interactions of the identified factors, we hypothesize that the combinatorial effects of these factors in rDFSC-CM might provide therapeutic benefits for the treatment of pulpitis.

Over the past decades, root canal treatment, which entails the removal of dental hard tissue and the entire pulp to eliminate intracanal infection, has been the therapy of choice for mature teeth with pulpitis. Inherent in this procedure is the loss of physiological and defensive functions of the pulp and the subsequent weakening of the treated teeth, which makes them more susceptible to fracture [64]. Therefore, the preservation of pulp with sustained vitality and the development of minimally invasive biological therapies have become key themes in contemporary regenerative endodontics [65]. Vital pulp therapy (VPT), in which the inflamed tissue is selectively removed and the exposed pulp is capped with bioactive materials $[66,67]$, provides an option to maintain the vitality of dental pulp under inflammatory conditions. Unfortunately, the most widely used capping materials, such as calcium hydroxide paste $\left(\mathrm{Ca}[\mathrm{OH}]_{2}\right)$ and mineral trioxide aggregate (MTA), are short of either anti-inflammatory or reparative properties, and the resins present in their formulations increase the cytotoxicity to pulp tissue, which limits the long-term success of VPT $[68,69]$. MSC-based biotherapy serves as a new therapeutic breakthrough. Various in vivo studies have shown the critical roles of MSCs as therapeutic agents in modulating inflammatory processes and encouraging functional recovery in acute kidney injury, spinal cord injury, experimental colitis, and skin wounds through paracrine pathways [10, 70-72]. A recent study found that DFSCs, a candidate MSC type for MSC-based therapy, downregulate the Th2-mediated immune response of mononuclear cells by secreting TGF- $\beta$ in patients with asthma [73]. We also showed that $\mathrm{rDFSC-CM}$ contains a rich cocktail of numerous soluble molecules, including immunomodulatory factors, growth factors, and neurotrophic factors [16]. The present study proves the favorable effects of rDFSC-CM in ameliorating inflammation and promoting the regeneration of the inflamed pulp and thus indicates the prospective application of rDFSC-CM in the development of novel capping agents for VPT or even in the treatment of other immune and inflammatory diseases. For successful clinical translation, protocols for DFSC isolation and ex vivo preparation will need to be optimized in future research.

\section{Conclusions}

In summary, the present study provides novel evidence showing that $\mathrm{rDFSC}-\mathrm{CM}$ exerts its therapeutic potential 


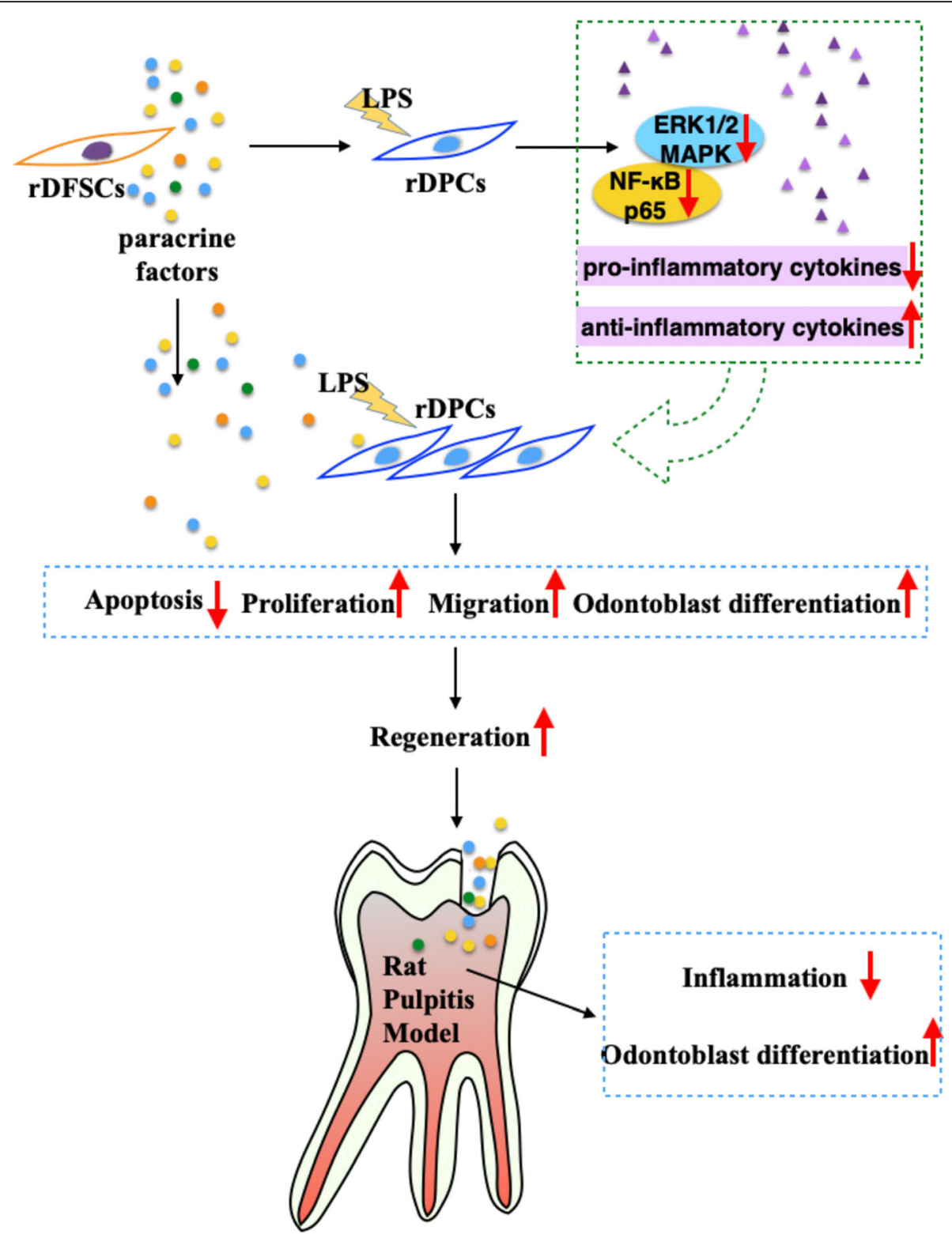

Fig. 8 rDFSC-CM remodels the inflammatory microenvironment of injured dental pulp

on pulpitis in vitro and in vivo through immunomodulatory pathways. rDFSC-CM exhibited an optimal capability to promote the regeneration of injured pulp by remodeling a proinflammatory microenvironment toward a regenerative microenvironment (Fig. 8). These findings confirmed our hypothesis, indicated that $\mathrm{rDFSC}-\mathrm{CM}$ is a prospective biotherapeutic agent, and shed new light on MSC-based therapeutic strategies for regenerative endodontics.

\section{Abbreviations}

MSC-miVPT: Mesenchymal stem cell-based minimally invasive vital pulp therapy; rDFSCs: Rat dental follicle stem cells; CM: Conditioned medium; LPS: Lipopolysaccharide; rDPCs: Rat dental pulp cells; SHEDs: Stem cells from human exfoliated deciduous teeth; AMPs: Antimicrobial peptides; IL: Interleukin; TNF-a: Tumor necrosis factor-a; TGF- $\beta$ : Transforming growth factor- $\beta$; IDO: Indoleamine 2,3-dioxygenase; PGE2: Prostaglandin E2;
HGF: Hepatocyte growth factor; TSP-1: Thrombospondin 1; FGF-2: Fibroblast growth factor 2; OPN: Osteopontin; VEGF: Vascular endothelial cell growth factor; NGFR: Nerve growth factor receptor; NRP-2: Neuropilin 2; MAPK: Mitogen-activated protein kinase; NF-KB: Nuclear factor-KB; ERK: Extracellular signal-regulated kinase; ALP: Alkaline phosphatase; DSPP: Dentin sialo phosphoprotein; Runx2: Runt-related transcription factor 2; BSP: Bone sialoprotein; DMP1: Dentin matrix acidic phosphoprotein 1; LTA: Lipoteichoic acid; $\mathrm{Ca}[\mathrm{OH}]_{2}$ : Calcium hydroxide paste; MTA: Mineral trioxide aggregate; CCK-8: Cell Counting Kit-8; S-D: Sprague-Dawley; aMEM: a-Minimum essential medium; PBS: Phosphate-buffered saline; HA/ TCP: Hydroxyapatite/tricalcium phosphate; RT-qPCR: Real-time quantitative polymerase chain reaction; HE: Hematoxylin-eosin; SD: Standard deviation; ANOVA: Analysis of variance

\section{Acknowledgements}

We would like to thank the Guangdong Provincial Key Laboratory of Stomatology, Sun Yat-sen University, for providing all experimental equipment. 


\section{Authors' contributions}

$\mathrm{HH}$ and $\mathrm{XC}$ performed most of the laboratory experiments and drafted the manuscript. KL and NW contributed to the data collection. ML and BY were responsible for the data analysis and interpretation. XW and XY were responsible for the study design, manuscript revising, and financial support. All authors have read and approved the final version of the manuscript.

\section{Funding}

This study was supported by grants from the National Natural Science Foundation of China (81970925, 81670983, and 81800956), Natural Science Foundation of Guangdong Province (2017A030308011 and 2018A030310330), and Guangdong Financial Fund for High-Caliber Hospital Construction (174-2018-XMZC-0001-03-0125/D-08).

\section{Availability of data and materials}

Please contact the author for data requests.

\section{Ethics approval and consent to participate}

The present work followed the Ethical Guidelines for Laboratory Animal Welfare determined by the University Ethics Committee of Zhongshan School of Medicine (ZSSOM) on Laboratory Animal Care, Sun Yat-sen University. The ethics committee approvals were obtained (Nos. 2017-194 and 2017-195)

\section{Consent for publication}

Not applicable.

\section{Competing interests}

The authors declare that they have no competing interests.

\section{Author details}

'Hospital of Stomatology, Guanghua School of Stomatology, Guangdong Provincial Key Laboratory of Stomatology, Sun Yat-sen University, Guangzhou 510055, People's Republic of China. ²Department of Stomatology, The Third Affiliated Hospital of Sun Yat-sen University, Guangzhou 510630, People's Republic of China. ${ }^{3}$ Key Laboratory of Green Chemistry and Technology, Ministry of Education, College of Chemistry, Sichuan University, Chengdu 610064, People's Republic of China.

Received: 12 May 2020 Revised: 27 June 2020 Accepted: 17 July 2020 Published online: 03 August 2020

\section{References}

1. Cooper PR, Chicca IJ, Holder MJ, Milward MR. Inflammation and regeneration in the dentin-pulp complex: net gain or net loss? J Endod. 2017:43(9s):S87-s94.

2. Xue D, Gong ZJ, Zhu FY, Qiu YJ, Li XD. Simvastatin increases cell viability and suppresses the expression of cytokines and vascular endothelial growth factor in inflamed human dental pulp stem cells in vitro. Adv Clin Exp Med. 2018;27(12):1615-23.

3. Cooper PR, Holder MJ, Smith AJ. Inflammation and regeneration in the dentin-pulp complex: a double-edged sword. J Endod. 2014;40(4 Suppl):S46-51.

4. Liu Y, Gao Y, Zhan X, Cui L, Xu S, Ma D, et al. TLR4 activation by lipopolysaccharide and Streptococcus mutans induces differential regulation of proliferation and migration in human dental pulp stem cells. J Endod. 2014:40(9):1375-81.

5. Li Z, Jiang CM, An S, Cheng Q, Huang YF, Wang YT, et al. Immunomodulatory properties of dental tissue-derived mesenchymal stem cells. Oral Dis. 2014;20(1):25-34.

6. Zhang QZ, Su WR, Shi SH, Wilder-Smith $P$, Xiang AP, Wong A, et al. Human gingiva-derived mesenchymal stem cells elicit polarization of m2 macrophages and enhance cutaneous wound healing. Stem Cells. 2010;28(10):1856-68.

7. Gao F, Chiu SM, Motan DA, Zhang Z, Chen L, Ji HL, et al. Mesenchymal stem cells and immunomodulation: current status and future prospects. Cell Death Dis. 2016;7:e2062.

8. Uccelli A, Moretta L, Pistoia V. Mesenchymal stem cells in health and disease. Nat Rev Immunol. 2008;8(9):726-36

9. Asami T, Ishii M, Namkoong $H$, Yagi K, Tasaka S, Asakura T, et al. Antiinflammatory roles of mesenchymal stromal cells during acute
Streptococcus pneumoniae pulmonary infection in mice. Cytotherapy. 2018;20(3):302-13.

10. Zullo JA, Nadel EP, Rabadi MM, Baskind MJ, Rajdev MA, Demaree CM, et al. The secretome of hydrogel-coembedded endothelial progenitor cells and mesenchymal stem cells instructs macrophage polarization in endotoxemia. Stem Cells Transl Med. 2015;4(7):852-61.

11. Blazquez R, Sanchez-Margallo FM, Alvarez V, Uson A, Casado JG. Surgical meshes coated with mesenchymal stem cells provide an anti-inflammatory environment by a M2 macrophage polarization. Acta Biomater. 2016;31:221-30.

12. Park HJ, Oh SH, Kim HN, Jung YJ, Lee PH. Mesenchymal stem cells enhance alpha-synuclein clearance via M2 microglia polarization in experimental and human parkinsonian disorder. Acta Neuropathol. 2016; 132(5):685-701.

13. Shi Y, Wang Y, Li Q, Liu K, Hou J, Shao C, et al. Immunoregulatory mechanisms of mesenchymal stem and stromal cells in inflammatory diseases. Nat Rev Nephrol. 2018;14(8):493-507.

14. Hoogduijn MJ, Lombardo E. Mesenchymal stromal cells anno 2019: dawn of the therapeutic era? Concise Rev Stem Cells Transl Med. 2019;8(11):1126-34.

15. Jimenez-Puerta GJ, Marchal JA, López-Ruiz E, Gálvez-Martín P. Role of mesenchymal stromal cells as therapeutic agents: potential mechanisms of action and implications in their clinical use. J Clin Med. 2020;9(2):445

16. Chen $X$, Yang B, Tian J, Hong H, Du Y, Li K, et al. Dental follicle stem cells ameliorate lipopolysaccharide-induced inflammation by secreting TGF-beta3 and TSP-1 to elicit macrophage M2 polarization. Cell Physiol Biochem. 2018:51(5):2290-308

17. Zhang X, Du Y, Ling J, Li W, Liao Y, Wei X. Dickkopf-related protein 3 negatively regulates the osteogenic differentiation of rat dental follicle cells. Mol Med Rep. 2017;15(4):1673-81.

18. Liao $C$, Wang $Y$, Ou Y, Wu Y, Zhou Y, Liang S. Effects of sclerostin on lipopolysaccharide-induced inflammatory phenotype in human odontoblasts and dental pulp cells. Int J Biochem Cell Biol. 2019;117: 105628

19. Lee SI, Kang SK, Jung HJ, Chun YH, Kwon YD, Kim EC. Muramyl dipeptide activates human beta defensin 2 and pro-inflammatory mediators through Toll-like receptors and NLRP3 inflammasomes in human dental pulp cells. Clin Oral Investig. 2015;19(6):1419-28.

20. Takegawa D, Nakanishi T, Hirao K, Yumoto H, Takahashi K, Matsuo T. Modulatory roles of interferon- $\gamma$ through indoleamine 2, 3dioxygenase induction in innate immune response of dental pulp cells. J Endod. 2014;40(9):1382-7.

21. Song $Z$, Lin $Z$, He F, Jiang L, Qin W, Tian $Y$, et al. NLRP3 is expressed in human dental pulp cells and tissues. J Endod. 2012;38(12):1592-7.

22. Wu H, He M, Yang R, Zuo Y, Bian Z. Astrocyte elevated gene-1 participates in the production of pro-inflammatory cytokines in dental pulp cells via NF-kappaB signalling pathway. Int Endod J. 2018;51(10): $1130-8$.

23. Moussa DG, Aparicio C. Present and future of tissue engineering scaffolds for dentin-pulp complex regeneration. J Tissue Eng Regen Med. 2019;13(1):58-75

24. Colombo JS, Moore AN, Hartgerink JD, D'Souza RN. Scaffolds to control inflammation and facilitate dental pulp regeneration. J Endod. 2014;40(4 Suppl):S612.

25. He W, Qu T, Yu Q, Wang Z, Lv H, Zhang J, et al. LPS induces IL-8 expression through TLR4, MyD88, NF-kappaB and MAPK pathways in human dental pulp stem cells. Int Endod J. 2013;46(2):128-36.

26. Zhu N, Chatzistavrou X, Ge L, Qin M, Papagerakis P, Wang Y. Biological properties of modified bioactive glass on dental pulp cells. J Dent. 2019;83:18-26.

27. Eramo $S$, Natali A, Pinna $R$, Milia E. Dental pulp regeneration via cell homing. Int Endod J. 2018:51(4):405-19.

28. Ok CY, Park S, Jang HO, Takata T, Bae MK, Kim YD, et al. Visfatin induces senescence of human dental pulp cells. Cells. 2020;9(1):193.

29. Alkharobi H, Beattie J, Meade J, Devine D, El-Gendy R. Dental pulp cells isolated from teeth with superficial caries retain an inflammatory phenotype and display an enhanced matrix mineralization potential. Front Physiol. 2017;8:244.

30. Wei $X$, Ling J, Wu L, Liu L, Xiao Y. Expression of mineralization markers in dental pulp cells. J Endod. 2007;33(6):703-8.

31. Yildirim S, Zibandeh N, Genc D, Ozcan EM, Goker K, Akkoc T. The comparison of the immunologic properties of stem cells isolated from human exfoliated deciduous teeth, dental pulp, and dental follicles. Stem Cells Int. 2016;2016:4682875 
32. Tomic S, Djokic J, Vasilijic S, Vucevic D, Todorovic V, Supic G, et al. Immunomodulatory properties of mesenchymal stem cells derived from dental pulp and dental follicle are susceptible to activation by toll-like receptor agonists. Stem Cells Dev. 2011;20(4):695-708.

33. Peng Z, Liu L, Wei X, Ling J. Expression of Oct-4, SOX-2, and MYC in dental papilla cells and dental follicle cells during in-vivo tooth development and in-vitro co-culture. Eur J Oral Sci. 2014;122(4):251-8.

34. Mo Z, Li Q, Cai L, Zhan M, Xu Q. The effect of DNA methylation on the miRNA expression pattern in lipopolysaccharide-induced inflammatory responses in human dental pulp cells. Mol Immunol. 2019;111:11-8.

35. Chen M, Copland DA, Zhao J, Liu J, Forrester JV, Dick AD, et al. Persistent inflammation subverts thrombospondin-1-induced regulation of retinal angiogenesis and is driven by CCR2 ligation. Am J Pathol. 2012;180(1):235-45.

36. Li A, Lao L, Wang Y, Xin J, Ren K, Berman BM, et al. Electroacupuncture activates corticotrophin-releasing hormone-containing neurons in the paraventricular nucleus of the hypothalammus to alleviate edema in a rat model of inflammation. BMC Complement Altern Med. 2008;8:20.

37. Wandinger KP, Lünemann JD, Wengert $O$, Bellmann-Strobl J, Aktas O, Weber A, et al. TNF-related apoptosis inducing ligand (TRAIL) as a potential response marker for interferon-beta treatment in multiple sclerosis. Lancet (London). 2003;361(9374):2036-43.

38. Gaskin FS, Kamada K, Zuidema MY, Jones AW, Rubin LJ, Korthuis RJ. Isoformselective 5'-AMP-activated protein kinase-dependent preconditioning mechanisms to prevent postischemic leukocyte-endothelial cell adhesive interactions. Am J Physiol Heart Circ Physiol. 2011;300(4):H1352-60.

39. Kim J, Park JC, Kim SH, Im Gl, Kim BS, Lee JB, et al. Treatment of FGF-2 on stem cells from inflamed dental pulp tissue from human deciduous teeth. Oral Dis. 2014;20(2):191-204.

40. Foster BL, Ao M, Salmon CR, Chavez MB, Kolli TN, Tran AB, et al. Osteopontin regulates dentin and alveolar bone development and mineralization. Bone. 2018;107:196-207.

41. Ngo VA, Jung JY, Koh JT, Oh WM, Hwang YC, Lee BN. Leptin induces odontogenic differentiation and angiogenesis in human dental pulp cells via activation of the mitogen-activated protein kinase signaling pathway. $J$ Endod. 2018;44(4):585-91.

42. Huojia M, Muraoka N, Yoshizaki K, Fukumoto S, Nakashima M, Akamine A, et al. TGF-beta3 induces ectopic mineralization in fetal mouse dental pulp during tooth germ development. Develop Growth Differ. 2005;47(3):141-52.

43. Xin BC, Wu QS, Jin S, Luo AH, Sun DG, Wang F. Berberine promotes osteogenic differentiation of human dental pulp stem cells through activating EGFRMAPK-Runx2 pathways. Pathol Oncol Res. 2020;26(3):1677-85.

44. Yuan B, Wu Z. MMP-2 silencing reduces the osteogenic transformation of fibroblasts by inhibiting the activation of the BMP/Smad pathway in ankylosing spondylitis. Oncol Lett. 2018;15(3):3281-6.

45. Xie J, Zhang D, Zhou C, Yuan Q, Ye L, Zhou X. Substrate elasticity regulates adipose-derived stromal cell differentiation towards osteogenesis and adipogenesis through $\beta$-catenin transduction. Acta Biomater. 2018;79:83-95.

46. Bae WJ, Yi JK, Park J, Kang SK, Jang JH, Kim EC. Lysyl oxidase-mediated VEGF-induced differentiation and angiogenesis in human dental pulp cells. Int Endod J. 2018;51(3):335-46.

47. Chen HI, Poduri A, Numi H, Kivela R, Saharinen P, McKay AS, et al. VEGF-C and aortic cardiomyocytes guide coronary artery stem development. J Clin Invest. 2014;124(11):4899-914.

48. Huang Y, Qi SH, Shu B, Chen L, Xie JL, Xu YB, et al. Fibroblast growth factorbinding protein facilitates the growth and migration of skin-derived precursors. J Cutaneous Med Surg. 2011;15(4):201-9.

49. Ouchi N, Oshima Y, Ohashi K, Higuchi A, Ikegami C, Izumiya Y, et al. Follistatin-like 1, a secreted muscle protein, promotes endothelial cell function and revascularization in ischemic tissue through a nitric-oxide synthase-dependent mechanism. J Biol Chem. 2008;283(47):32802-11.

50. Hadjichristou C, Papachristou E, Bonovolias I, Bakopoulou A. Threedimensional tissue engineering-based Dentin/Pulp tissue analogue as advanced biocompatibility evaluation tool of dental restorative materials. Dent Mater. 2020;36(2):229-48.

51. Bhattarai P, Cosacak MI, Mashkaryan V, Demir S, Popova SD, Govindarajan N, et al. Neuron-glia interaction through Serotonin-BDNF-NGFR axis enables regenerative neurogenesis in Alzheimer's model of adult zebrafish brain. PLoS Biol. 2020;18(1):e3000585.

52. Goel HL, Chang C, Pursell B, Leav I, Lyle S, Xi HS, et al. VEGF/neuropilin-2 regulation of Bmi-1 and consequent repression of IGF-IR define a novel mechanism of aggressive prostate cancer. Cancer Discov. 2012;2(10):906-21.
53. Berteotti C, Lo Martire V, Alvente S, Bastianini S, Matteoli G, Silvani A, et al. Effect of ambient temperature on sleep breathing phenotype in mice: the role of orexins. J Exp Biol. 2020;223(Pt 13):jeb219485.

54. Bergamin E, Hallock PT, Burden SJ, Hubbard SR. The cytoplasmic adaptor protein Dok7 activates the receptor tyrosine kinase MuSK via dimerization. Mol Cell. 2010;39(1):100-9.

55. Dolatshad NF, Silva AT, Saffrey MJ. Identification of GFR alpha-2 isoforms in myenteric plexus of postnatal and adult rat intestine. Brain Res Mol Brain Res. 2002;107(1):32-8.

56. Schmitt K, Holsboer-Trachsler E, Eckert A. BDNF in sleep, insomnia, and sleep deprivation. Ann Med. 2016;48(1-2):42-51.

57. Lao G, Ren M, Wang X, Zhang J, Huang Y, Liu D, et al. Human tissue inhibitor of metalloproteinases-1 improved wound healing in diabetes through its anti-apoptotic effect. Exp Dermatol. 2019;28(5):528-35.

58. Thang NM, Kumasawa K, Tsutsui T, Nakamura H, Masaki H, Ono T, et al. Overexpression of endogenous TIMP-2 increases the proliferation of BeWo choriocarcinoma cells through the MAPK-signaling pathway. Reprod Sci (Thousand Oaks). 2013;20(10):1184-92.

59. Lampert F, Stafa D, Goga A, Soste MV, Gilberto S, Olieric N, et al. The multisubunit GID/CTLH E3 ubiquitin ligase promotes cell proliferation and targets the transcription factor Hbp1 for degradation. eLife. 2018;7:e35528.

60. Orime K, Shirakawa J, Togashi Y, Tajima K, Inoue H, Ito Y, et al. Trefoil factor 2 promotes cell proliferation in pancreatic $\beta$-cells through CXCR-4-mediated ERK1/2 phosphorylation. Endocrinology. 2013;154(1):54-64.

61. Liu L, Shu S, Cheung GS, Wei X. Effect of miR-146a/bFGF/PEG-PEl nanoparticles on inflammation response and tissue regeneration of human dental pulp cells. Biomed Res Int. 2016;2016:3892685.

62. Becktor KB, Hansen BF, Nolting D, Kjaer I. Spatiotemporal expression of NGFR during pre-natal human tooth development. Orthod Craniofac Res. 2002;5(2):85-9.

63. Wang J, Huang Y, Zhang J, Xing B, Xuan W, Wang H, et al. NRP-2 in tumor lymphangiogenesis and lymphatic metastasis. Cancer Lett. 2018;418:176-84.

64. Wolters WJ, Duncan HF, Tomson PL, Karim IE, McKenna G, Dorri M, et al. Minimally invasive endodontics: a new diagnostic system for assessing pulpitis and subsequent treatment needs. Int Endod J. 2017;50(9):825-9.

65. European Society of Endodontology developed b, Duncan HF, Galler KM, Tomson PL, Simon S, El-Karim I, et al. European Society of Endodontology position statement: management of deep caries and the exposed pulp. Int Endod J. 2019;52(7):923-34.

66. Lin LM, Ricucci D, Saoud TM, Sigurdsson A, Kahler B. Vital pulp therapy of mature permanent teeth with irreversible pulpitis from the perspective of pulp biology. Aust Endod J. 2020;46(1):154-66.

67. Ricucci D, Siqueira JF Jr, Li Y, Tay FR. Vital pulp therapy: histopathology and histobacteriology-based guidelines to treat teeth with deep caries and pulp exposure. J Dent. 2019;86:41-52.

68. Chen L, Suh Bl. Cytotoxicity and biocompatibility of resin-free and resinmodified direct pulp capping materials: a state-of-the-art review. Dent Mater J. 2017;36(1):1-7.

69. Howard J, Gardner L, Saifee Z, Geleil A, Nelson I, Colombo JS, et al. Synthesis and characterization of novel calcium phosphate glass-derived cements for vital pulp therapy. J Mater Sci Mater Med. 2020;31(1):12.

70. Nakajima H, Uchida K, Guerrero A, Watanabe S, Sugita D, Takeura N, et al. Transplantation of mesenchymal stem cells promotes an alternative pathway of macrophage activation and functional recovery after spinal cord injury. J Neurotrauma. 2012;29(8):1614-25.

71. Simovic Markovic B, Nikolic A, Gazdic M, Nurkovic J, Djordjevic I, Arsenijevic N, et al. Pharmacological inhibition of Gal-3 in mesenchymal stem cells enhances their capacity to promote alternative activation of macrophages in dextran sulphate sodium-induced colitis. Stem Cells Int. 2016;2016:2640746.

72. Huang SC, Everts B, Ivanova Y, O'Sullivan D, Nascimento M, Smith AM, et al. Cell-intrinsic lysosomal lipolysis is essential for alternative activation of macrophages. Nat Immunol. 2014;15(9):846-55.

73. Genc D, Zibandeh N, Nain E, Gokalp M, Ozen AO, Goker MK, et al. Dental follicle mesenchymal stem cells down-regulate Th2-mediated immune response in asthmatic patients mononuclear cells. Clin Exp Allergy. 2018; 48(6):663-78.

\section{Publisher's Note}

Springer Nature remains neutral with regard to jurisdictional claims in published maps and institutional affiliations. 